\title{
Industrial postdoc: choosing a different path
}

\author{
Aida Sivro, Ph.D.
}

While the number of Ph.D. graduates has been on a steady increase throughout the world, the number of academic positions has been continuously declining. An article in The Economist in 2010 reported that USA produced 100,000 doctoral degrees between 2005 and 2009, while in the same period there were only 16,000 new professorships. Moreover, according to the National Institute of Health $(\mathrm{NIH})$, only $26 \%$ of Ph.D. graduates from biomedical sciences obtained tenured track positions in 2012. With the lack of academic positions, an increasing number of Ph.D. graduates are choosing industry over academia. A 2006 article in Science estimated that in 2001 industry employed 35\% of life science Ph.D.s, an increase from 15\% in 1981. For Ph.D.s who would like to experience working in the industry setting but keep the academia dream alive, there is a new option on the table: industrial postdoc. Undertaking an industry postdoc is likely the best way to get introduced to the culture of research and development in the private sector. It is a unique opportunity to design and perform research in a pharmaceutical setting with guidance and support from industry-based investigators.

From the perspective of a Ph.D. graduate, an obvious benefit to industry is increased salaries and benefits. Most postdoctoral placements in Canada and the USA pay their postdocs approximately $\$ 40,000$ per year. Annual starting salary at Genentech is $\$ 63,000$ with a promise of increase each year based on satisfactory performance. In addition, postdocs are eligible for the following benefits: medical, dental, and vision; life and disability insurance; 401(k); 12 paid holidays; and 3 weeks of vacation time.

Another benefit to working in industry is the access to state-of-theart equipment and facilities, as well as a wide variety of expertise ranging from bioinformatics to chemistry, and biology. A large advantage to doing research in industry is that there is usually more funding allocated for each project, leaving you able to pursue your scientific questions without worrying about funding or grant writing. This access to resources can significantly speed up your scientific research and discoveries while making you more competitive for both academia and industry jobs.

\section{Things to consider}

Will an industrial postdoc cut you off from a career in academia? It is commonly believed that working in industry makes it difficult to return to academia, which is the reason why most Ph.D. graduates take a postdoc position. However: is this truly the case? Two things are likely to be most important if you are looking for a career in academia: networking, and the quantity and quality of one's publications. The lines between academia and industry are becoming increasingly blurred, and partnerships between the two are on the rise. Through your industrial postdoc you are likely to come into contact with scientists from various disciplines, from both the industrial and academic sector. Becoming an 'industry-academia' hybrid could provide you with valuable contacts on both sides and significantly increase your market value.

Since publications are crucial for obtaining an academic position, postdoc experience should more than anything become the time to build a strong publication record and improve your CV. Several pharmaceutical companies (e.g. Novartis and AstraZeneca) specifically state on their postdoctoral job advertisements that they encourage publishing and conference presentations. However, as with any academic placement, your publication record will ultimately depend on the project, supervisor, and quality of your results. Before committing to an industrial placement you need to discuss this with a prospective employer. For instance, Genentech postdocs are kept away from any research that involves development of a product. 
This allows the fellows to openly present and discuss their research at conferences and continue working on their projects once they leave the company. Similarly, Novartis Institutes for Biomedical Research (NIBR) do not place restrictions on postdoctoral publications, and projects are designed with this in mind. For postdoctoral fellows looking to pursue a career in academia, the NIBR program offers the opportunity to apply for a NIBR Young Investigator Development Award, a grant to continue research for an additional year at NIBR as well as three years as a tenure track faculty member at an accredited academic institution. Some postdoctoral fellows may wilfully choose to work on a project that cannot be published, considering the potential benefit of being an inventor on a patent and choose a different career path to the one in academia.

Will the industrial postdoc position guarantee you a job in the company later on? Postdoctoral appointments typically lead to permanent positions at some companies, but this is not a rule. Certain companies like AstraZeneca aim to retain their fellows as permanent employees. This is not the case with companies such as Genentech, where only about $10 \%$ of postdocs end up being hired by the company as scientists.

\section{How to apply?}

Industrial postdoctoral appointments vary in scope, length and application process depending on the company. As with any research placement, it is important to select a position that excites you; the salary alone will not be enough to motivate your work if you find the work and science uninteresting. Industry will have a list of opened projects and proposed supervisors. It is important to contact other postdoctoral fellows in the laboratory and determine the work and supervision style of the research group. Some companies like NIBR and Genentech have a formal application process managed through a centralized office. In other companies such as AstraZeneca, prospective postdocs apply to the human resource department in response to a specific position listed on the company's websites. In some cases it may be possible to obtain a position by contacting a researcher of interest directly.
Some of the pharmaceutical companies with industrial post-doc opportunities include:

- Roche (http://www.roche.com/careers/workplaces/ wp_research/postdoc_fellowship_rpf_program.htm)

- Genentech (http://www.gene.com/careers/academicprograms/postdocs)

- NOVARTIS Institutes for Biomedical Research (http:// postdoc.nibr.com)

- MERCK (http://www.merck.com/research/fellow/ home.html )

- GlaxoSmithKline (http://www.gsk.com/en-gb/ careers/postgraduates/randd-postdoctoral-globaltraining-programme/)

- AstraZeneca (http://www.astrazenecacareers.com/ students/programmes/postdoc/)

- Pfizer (http://pfizercareers.com/university-relations/ postdoc)

\section{Aida Sivro, Ph.D.}

Aida Sivro is a postdoctoral fellow at Centre for AIDS Programme of Research in South Africa (CAPRISA) and department of Medical MIcrobiology, University of Manitoba. Her current research interests include studying the predictors of HIV acquistion and pathogenesis. 